\title{
KEPUASAN MEMEDIASI KUALITAS LAYANAN DAN CITRA PERUSAHAAN DENGAN LOYALITAS PELANGGAN LION AIR DI KOTA DENPASAR
}

\author{
Komang Diah Hadi Paramita \\ Ida Bagus Sudiksa ${ }^{2}$
}

${ }^{1,2}$ Fakultas Ekonomi dan Bisnis Universitas Udayana (Unud), Bali, Indonesia email : paramitahadi@yahoo.com

\begin{abstract}
ABSTRAK
Penelitian ini bertujuan untuk mengetahui Peran Kepuasan Memediasi Kualitas Layanan dan Citra Perusahaan dengan Loyalitas Pelanggan Lion Air di Kota Denpasar. Penelitian dilakukan di kota Denpasar dan merupakan penelitian asosiatif. Sampel penelitian berjumlah 112 responden dengan menggunakan metode Non Probability Sampling - Purposive Sampling. Teknik analisis data pada penelitian ini adalah analisis jalur (path analysis) dan uji sobel yang dihitung menggunakan SPPS for windows. Penelitian ini menemukan baik kualitas layanan maupun citra perusahaan, keduanya memiliki pengaruh positif dan signifikan terhadap kepuasan. Kualitas layanan, citra perusahaan serta kepuasan memiliki pengaruh positif dan signifikan terhadap loyalitas pelanggan. Kepuasan mampu memediasi kualitas layanan dan citra perusahaan dengan loyalitas pelanggan.
\end{abstract}

Kata kunci : kualitas layanan, citra perusahaan, kepuasan, loyalitas pelanggan

\begin{abstract}
This study aims to identify the factors that make a passenger loyal to an airline in Denpasar city by investigating the impact of service quality and corporate image through satisfaction as mediating variable. This study belongs to associative research with 112 respondents in total collected through purposive sampling. Responses are analyzed using Path Analysis and Sobel Test. Results reveal that each variable, service quality and corporate has positive and significant impact on satisfaction. Furthermore, service quality, and satisfaction have positive and significant impact on passenger loyalty. Lastly, this study finds that service quality and corporate image have positive impact on passenger loyalty through satisfaction.
\end{abstract}

Keywords : service quality, corporate image, satisfaction, customer loyalty 


\section{PENDAHULUAN}

Lion Air merupakan salah satu maskapai penerbangan LCC yang menguasai pangsa pasar khususnya untuk penerbangan domestik. Kementerian Perhubungan mencatat pada Tahun 2015 Lion Air kembali menjadi penguasa pangsa pasar domestik karena Air mampu mengangkut penumpang sebanyak 26,38 juta orang atau 35 persen dari total penumpang domestik yaitu sebanyak 76,62 juta penumpang. (http://hubud.dephub.go.id.).

Maraknya jasa layanan penerbangan murah selama beberapa tahun terakhir tidak diimbangi dengan kualitas layanan maskapai yang maksimal sehingga banyak konsumen yang merasa dirugikan. World Airline Rating, merilis 21 maskapai penerbangan dengan kualitas di bawah standar.

Tabel 1.

Maskapai dengan Kualitas di Bawah Standar Versi Skytrax

\begin{tabular}{cccc}
\hline No & Nama Maskapai & $\begin{array}{c}\text { Kategori } \\
\text { Bintang } \\
\text { Penilaian }\end{array}$ & $\begin{array}{c}\text { Rating Pengguna } \\
(\mathbf{0} / \mathbf{1 0})\end{array}$ \\
\hline 1 & Air Kyoro & $*$ & $6 / 10$ \\
2 & Bahamas Air & $* *$ & $3 / 10$ \\
3 & Biman Bangladesh & $* *$ & $6 / 10$ \\
4 & Bulgaria Air & $* *$ & $6 / 10$ \\
5 & China United Airlines & $* *$ & $5 / 10$ \\
6 & Cubana Airlines & $* *$ & $4 / 10$ \\
7 & Iran Air & $* *$ & $6 / 10$ \\
8 & Lion Air & $* *$ & $4 / 10$ \\
9 & Mahan Air & $* *$ & $7 / 10$ \\
10 & Nepal Airlines & $* *$ & $7 / 10$ \\
11 & Onur Air & $* *$ & $6 / 10$ \\
12 & Pegasus Airlines & $* *$ & $5 / 10$ \\
13 & Rossiya Airlines & $* *$ & $6 / 10$ \\
14 & Smartwings & $* *$ & $5 / 10$ \\
15 & Spirit Airlines & $* *$ & $3 / 10$ \\
16 & Sudan Airways & $* *$ & $1 / 10$ \\
17 & Syrianair & $* *$ & $3 / 10$ \\
18 & Tajik Air & $* *$ & $0 / 10$ \\
19 & Turkmenistan Airlines & $* *$ & $4 / 10$ \\
20 & Ukraine Int'l Airlines & $* *$ & $5 / 10$ \\
21 & Yemenia & & $4 / 10$ \\
\hline
\end{tabular}

Sumber : www.airlinequality.com 
Berdasarkan Tabel 1. Lion Air masuk pada kategori 2 - Star Airline Rating, yaitu rating yang diberikan kepada maskapai penerbangan dengan kualitas layanan yang rendah dan umumnya berada di bawah kualitas rata - rata pada berbagai aspek penilaian. Kategori 2 - Star Airline Rating menandakan bahwa layanan produk, staf, dan layanan kabin yang kurang atau tidak konsisten. Penilaian pengguna secara keseluruhan adalah seebsar 4 dari nilai tertinggi 10 dengan jumlah total 104 reviews. Adapun keluhan yang umumnya disampaikan oleh pengguna antara lain delay, cabin crew yang kurang informatif, kurangnya fasilitas entertainment, kabin yang panas dan sebagainya.

Jika Lion Air hanya menawarkan harga murah dan mengesampingkan kualitas layanan serta citra perusahaan mereka, pelanggan - pelanggan yang merasa tidak puas memiliki potensi untuk berpindah ke maskapai lainnya. Bertambahnya pesaing tentunya merupakan ancaman bagi perusahaan sejenis. Salah satu hal yang harus diperhatikan maskapai penerbangan agar bisa bertahan dalam persaingan yang semakin intens adalah loyalitas pelanggan (Yunus et al., 2013).

Hasil penelitian awal melalui wawancara berdasarkan kuesioner pada sampel 20 orang responden di Kota Denpasar menemukan bahwa 33\% atau 7 orang merasa puas dengan kinerja Lion Air. Sementara itu, sebanyak 9 orang (45\%) menyatakan tidak puas dengan kualitas layanan dan citra Lion Air. Sisanya, sebanyak 4 orang (22\%) meragukan kepuasan yang mereka rasakan selama menggunakan jasa maskapai penerbangan Lion Air.

Sementara itu, sebanyak $15 \%$ atau 3 orang responden menyatakan loyal dengan Lion Air. Responden enggan berganti ke maskapai lainnya karena mereka 
merasa kualitas Lion Air sudah cukup baik dan sesuai dengan harga yang ditawarkan. 8 orang responden (42\%) meragukan apakah mereka akan loyal dengan Lion Air. Responden cenderung menemukan inkonsistensi dari kualitas layanan yang selama ini diterima, selain itu citra maskapai penerbangan Lion Air sebagai penguasa marketshare belum ditunjang oleh kemampuan mereka dalam menjaga hubungan yang baik dengan pelanggan. Sementara itu, sebanyak 9 orang berpendapat bahwa mereka akan menggunakan Lion Air dengan tetap mempertimbangkan maskapai penerbangan lainnya.

Beberapa penelitian sebelumnya juga menemukan adanya keterkaitan antara kualitas layanan, citra perusahaan, kepuasan dan loyalitas pelanggan. Safitri dkk. (2016) menemukan adanya pengaruh yang signifikan antara kualitas layanan dan kepuasan pelanggan. Namun, temuan ini berbeda dengan hasil penelitian Wijayanto (2015) yang menemukan bahwa tidak semua dimensi kualitas layanan berpengaruh signifikan terhadap kepuasan nasabah bank.

Penelitian yang dilakukan oleh Safitri dkk. (2016) menemukan bahwa semakin baik citra perusahaan dan mampu memberikan kepuasan kepada pelanggannya maka semakin tinggi loyalitas pelanggan tersebut. Hal ini berbeda dengan hasil penelitian Saputra (2013) yang menemukan bahwa citra perusahaan yang baik dapat berpengaruh sebaliknya pada loyalitas pelanggan, namun semakin baik citra sebuah perusahaan yang dipersepsikan oleh pelanggan maka loyalitas pelanggan akan meningkat melalui kepuasan pelanggan sebagai pemediasi.

Berdasarkan latar belakang yang telah dipaparkan, adapun rumusan masalah yang muncul dalam penelitian ini adalah bagaimana pengaruh kualitas layanan 
terhadap kepuasan pelanggan Lion Air di Kota Denpasar, bagaimana pengaruh citra perusahaan terhadap kepuasan pelanggan Lion Air di Kota Denpasar, bagaimana pengaruh kualitas layanan terhadap loyalitas pelanggan Lion Air di Kota Denpasar, bagaimana pengaruh citra perusahaan terhadap loyalitas pelanggan Lion Air di Kota Denpasar, bagaimana pengaruh kepuasan terhadap loyalitas pelanggan Lion Air di Kota Denpasar, bagaimana peran kepuasan memediasi kualitas layanan dengan loyalitas pelanggan Lion Air di Kota Denpasar, bagaimana peran kepuasan memediasi citra perusahaan dengan loyalitas pelanggan Lion Air di Kota Denpasar.

Tujuan penelitian ini adalah untuk menjelaskan pengaruh kualitas layanan terhadap kepuasan pelanggan Lion Air di Kota Denpasar, untuk menjelaskan pengaruh citra perusahaan terhadap kepuasan pelanggan Lion Air di Kota Denpasar, untuk menjelaskan pengaruh kualitas layanan terhadap loyalitas pelanggan Lion Air di Kota Denpasar, untuk menjelaskan pengaruh citra perusahaan terhadap loyalitas pelangga Lion Air di Kota Denpasar, untuk menjelaskan pengaruh kepuasan terhadap loyalitas pelanggan Lion Air di Kota Denpasar, untuk menjelaskan peran kepuasan memediasi pengaruh kualitas layanan dengan loyalitas pelanggan Lion Air di Kota Denpasar, untuk menjelaskan peran kepuasan memediasi pengaruh citra perusahaan dengan loyalitas pelanggan Lion Air di Kota Denpasar.

Kegunaan teoritis penelitian ini dapat memberi sumbangan empiris tentang pengaruh variabel kualitas layanan dan citra perusahaan terhadap loyalitas pelanggan yang dimediasi oleh kepuasan pelanggan dan menambah refrensi untuk studi selanjutnya. Keguaan praktis penelitian ini adalah memberikan masukan dan 
pertimbangan khususnya bagi maskapai penerbangan Lion Air dan maskapai penerbangan lainnya untuk memahami pentingnya kualitas layanan, citra perusahaan, dan kepuasan konsumen untuk mempertahankan loyalitas pelanggan

Tjiptono dkk. (2012:387) mengatakan bahwa loyalitas pelanggan adalah komitmen pelanggan terhadap suatu merek, toko, atau pemasok, berdasarkan sikap yang positif dan tercermin dalam pembelian ulang yang konsisten. Salah satu contoh sikap positif yang diberikan oleh pelanggan yang telah loyal antara lain pembelian ulang, berusaha mencari produk dari satu perusahaan meskipun berada ditempat yang jauh dan juga tidak lagi mempertimbangkan merek lain untuk dibeli selain merek produk yang sering dibeli.

Kepuasan adalah perasaan senang atau kecewa seseorang yang muncul setelah membandingkan kinerja (hasil) produk yang dipikirkan terhadap kinerja yang diharapkan (Kotler \& Keller, 2009:177). Menurut Sumarwan dkk. (2010:261) kepuasan adalah tingkat perasaan setelah membandingkan kinerja atau hasil yang dirasakan dengan harapannya.

Menurut Kotler \& Keller (2009 : 143) kualitas adalah total fitur dan karakteristik produk atau jasa yang bergantung pada kemampuannya untuk memuaskan kebutuhan yang dinyatakan atau tersirat. Parasuraman et al. (1988) mendefiniskan kualitas layanan sebagai perbandingan antara layanan yang dipersepsikan konsumen dengan layanan yang diharapkan konsumen. Apabila jasa yang diterima atau dirasakan sudah sesuai dengan apa yang diharapkan oleh pengguna jasa berarti kualitas pelayanan baik dan memuaskan, tetapi jika jasa yang diterima melebihi ekspektasi pengguna jasa tersebut, maka kualitas pelayanan 
dipersepsikan sangat baik dan berkualitas. Sebaliknya, ketika manfaat dari jasa yang dikonsumsi lebih rendah dari ekspektasi, kualitas pelayanan akan dipersepsikan buruk.

Steinmetz dalam Sutojo (2004:1) menambahkan definisi citra sebagai pancaran atau reproduksi jati diri atau benak perorangan, benda atau organisasi. Suatu produk yang mendapat perhatian yang besar dan citra yang positif akan menghasilkan kesetiaan konsumen yang lebih besar dan mengurangi bahaya akan adanya persaingan yang ada, jadi dapat disimpulkan dengan memiliki citra perusahaan yang luas di masyarakat akan dapat menghasilkan calon-calon pelanggan yang loyal dan juga dapat memperluas pangsa pasar produk suatu perusahaan (Kotler, $2008: 20)$.

Penelitian P.Singh \& Takur (2012), Kaura et al. (2015), serta Djanas (2016) menyebutkan bahwa kualitas layanan berpengaruh positif dan signifikan terhadap kepuasan. Sementara itu penelitian yang dilakukan oleh Wijayanto (2015) menemukan bahwa tidak semua dimensi kualitas layanan berpengaruh signifikan terhadap kepuasan. Sebelumnya lebih banyak ditemukan bahwa kualitas layanan berpengaruh positif dan signifikan yang ada maka dapat dirumuskan hipotesis sebagai berikut :

$\mathrm{H}_{1}$ : Kualitas layanan berpengaruh positif dan signifikan terhadap kepuasan.

Penelitian yang dilakukan Abd-El-Salam et al., (2013), Anisimova (2013), Abrudan et al. (2015), dan Sia \& Subagio (2013) memukan bahwa citra perusahaan berpengaruh positif dan signifikan terhadap kepuasan. Hal ini berbanding terbalik 
dengan penelitian Sondakh (2014) yang menemukan citra merek berpengaruh tidak signifikan terhadap kepuasan. Hasil penelitian sebelumnya lebih banyak menemukan bahwa citra perusahaan berpengaruh positif dan signfikan terhadap kepuasan, sehingga dirumuskan hipotesis sebagai berikut :

$\mathrm{H}_{2} \quad$ : Citra perusahaan berpengaruh positif dan signifikan terhadap kepuasan.

Anisimova (2013) menemukan bahwa kualitas layanan memiliki pengaruh yang positif terhadap kepuasan. Selain itu, Muntholimah \& Rahayu (2014) menemukan bahwa kualitas layanan bepengaruh signifikan terhadap loyalitas pengguna jasa pengiriminan JNE Surabaya. Selanjutnya, penelitian yang dilakukan Yunnus et al. (2013) mengenai loyalitas konsumen maskapai penerbangan LCC domestik Malaysia menemukan bahwa kualitas layanan mempengaruhi loyalitas konsumen terhadap maskapai penerbangan. Hasil penelitian sebelumnya lebih banyak ditemukan kualitas layanan berpengaruh positif dan signifikan terhadap loyalitas, sehingga dapat dirumuskan hipotesis sebagai berikut :

$\mathrm{H}_{3} \quad$ : Kualitas layanan berpengaruh positif dan signifikan terhadap loyalitas pelanggan.

Penelitian yang dilakukan oleh Kaur \& Soch (2012) menemukan bahwa citra perusahaan merupakan determinan yang penting dalam attidudinal loyalty. Hal ini didukung oleh penelitian yang dilakukan Singh (2014) yang bahwa untuk mengembangkan konsumen loyal perusahaan wajib meningkatkan citra perusahaan dan mengembangkan loyalitas terhadap perusahaan yang akan menghasilkan brand loyalty. Selain itu Normasari dkk. (2013) menemukan bahwa citra perusahaan 
secara langsung memiliki pengaruh yang signifikan terhadap loyalitas pelanggan. Hasil penelitian tersebut berbeda dari hasil penelitian Wungow (2013) juga menemukan bahwa citra tidak berpengaruh signifikan terhadap loyalitas. Penelitian - penelitian empiris sebelumnya lebih banyak ditemukan citra perusahaan berpengaruh positif dan signifikan terhadap loyalitas, sehingga hipotesis yang dirumuskan adalah

$\mathrm{H}_{4}$ : Citra perusahaan berpengaruh positif dan signifikan terhadap loyalitas pelanggan.

Penelitian Singh \& Takur (2012) menemukan bahwa kepuasan berperan penting untuk meningkatkan loyalitas pelanggan, pengguna mungkin lebih loyal jika mereka puas. Hal ini sesuai dengan penelitian Izogo \& Ogba (2014) yang menyatakan bahwa kepuasan konsumen berpengaruh positif dan signifikan terhadap loyalitas. Selain itu, Ganiyu et al. (2012) juga menemukan bahwa kepuasan memiliki pengaruh yang positif terhadap loyalitas hal ini berbeda dengan penelitian yang dilakukan oleh Huda \& Wahyuni (2012) tentang loyalitas nasabah BRI di Jakarta. Huda \& Wahyuni (2012) menemukan bahwa tingkat kepuasan tidak memiliki pengaruh positif dan signifikan terhadap loyalitas. Nasabah yang puas terhadap pelayanan perusahaan belum tentu membuat dirinya menjadi loyal atau setia terhadap perusahaan tersebut. Penelitian - penelitian empiris sebelumnya dimana lebih banyak ditemukan kepuasan berpengaruh positif dan signifikan terhadap loyalitas maka dirumuskan hipotesis sebagai berikut:

$\mathrm{H}_{5} \quad$ : Kepuasan berpengaruh positif dan signifikan terhadap loyalitas pelanggan 
Penelitian yang dilakukan Kaura et al. (2014) tentang loyalitas konsumen di sektor jasa perbankan di India menemukan bahwa bahwa kepuasan pelanggan mempengaruhi loyalitas. Selain itu Putri dkk. (2015) dan menemukan bahwa loyalitas pelanggan timbul dari kualitas pelayanan perusahaan yang sesuai harapan atau ekspektasi akhirnya akan menyebabkan kepuasan pelanggan. Namun, penelitian yang dilakukan oleh Singh \& Takur (2012) menemukan bahwa kepuasan hanya mampu memediasi 2 dari total 5 dimensi kualitas yaitu tangibility dan emphaty dengan loyalitas. Kepuasan tidak mampu memediasi dimensi kualitas lainnya yaitu responsiveness, realibility, dan tangibles. Penelitian - penelitian empiris sebelumnya lebih banyak ditemukan bahwa kepuasan mampu memediasi kualitas layanan dengan loyalitas, sehingga dapat dirumuskan hipotesis sebagai berikut :

$\mathrm{H}_{6}$ : Kepuasan memediasi kualitas layanan dengan loyalitas pelanggan.

Penelitian Safitri dkk. (2016) menemukan bahwa citra perusahaan memiliki pengaruh tidak langsung terhadap loyalitas pelanggan melalui kepuasan pelanggan. Selanjutnya, penelitian yang dilakukan oleh Saputra (2013) menemukan bahwa citra perusahaan yang baik dapat meningkatkan loyalitas pelanggan melalui kepuasan pelanggan, hal ini dapat dilihat pada hasil uji signifkansi menunjukkan mediasi sempurna terhadap loyalitas pelanggan. Sedangkan penelitian yang dilakukan oleh Tjandra dkk. (2016) menemukan bahwa hubungan langsung antara citra perusahaan dengan loyalitas pelanggan lebih kuat dibandingkan dengan menggunakan kepuasan sebagai variabel mediasi. Artinya, kepuasan pelanggan dianggap sebagai mediator yang kurang dalam memediasi pengaruh dari citra 
perusahaan terhadap pembentukan loyalitas pelanggan. Penelitian - penelitian empiris sebelumnya lebih banyak ditemukan bahwa kepuasan mampu memediasi kualitas citra perusahaan dengan loyalitas, maka dirumuskan hipotesis sebagai berikut maka berikut :

$\mathrm{H}_{7} \quad$ : Kepuasan memediasi citra perusahaan dengan loyalitas pelanggan.

\section{METODE PENELITIAN}

Penelitian dilakukan di Kota Denpasar. Jenis data pada penelitian ini adalah data kualitatif dan kuantitatif. Data kualitatif pada penelitian ini adalah gambaran umum tentang pelanggan maskapai penerbangan Lion Air di Kota Denpasar dan penilaian responden terhadap pernyataan-pernyataan yang ada di dalam kuesioner. Data kuantitatif pada penelitian ini adalah skor jawaban responden dan hasil kuesioner yang disebarkan meliputi pendidikan, jenis pekerjaan, dan rating Lion Air oleh pengguna situs Skytrax. Sumber data pada penelitian ini adalah primer dan sekunder. Sumber primer adalah hasil kuesioner atau jawaban dari responden yang sesuai dengan kriteria sampel. Sumber sekunder adalah kajian pustaka, baik berupa literatur, jurnal, dan situs internet resmi dari Skytrax, Kementrian Perhubungan Nasional, Badan Pusat Statistik, dan sportal berita terpercaya seperti Tempo.

Penelitian ini memiliki beberapa variabel yang akan dianalisis. Vaiabel tersebut antara lain adalah kualitas layanan $\left(\mathrm{X}_{1}\right)$ dan citra perusahaan $\left(\mathrm{X}_{2}\right)$ sebagai variabel independen, kepuasan $\left(\mathrm{Y}_{1}\right)$ sebagai variabel memediasi, serta loyalitas pelanggan $\left(\mathrm{Y}_{2}\right)$ sebagai variabel dependen. Populasi yang diteliti adalah pelanggan Lion Air berdomisili di Kota Denpasar dan sudah pernah menggunakan jasa 
penerbangan maskapai Lion Air minimal 2 kali. Non-probability sampling merupakan metode penentuan sampel yang digunakan pada penelitian ini dan teknik yang dipilih dari metode tersebut adalah purposive sampling. Kriteria penentuan sampel antara lain responden berpendidikan minimal SMA/sederajat, berdomisili di Kota Denpasar, dan pernah menggunakan jasa maskapai penerbangan Lion Air minimal 2 kali. Metode pengumpulan data yang digunakan adalah dengan metode survey dengan teknik wawancara menggunakan kuisioner. Setiap pernyataan pada kuesioner diukur dengan skala Likert. Analisis jalur (path analysis) digunakan sebagai teknik analisis data.

Adapun dengan langkah-langkah analisis jalur adalah sebagai berikut:

Langkah pertama, merumuskan hipotesis dan persamaan struktural

Model I

Hipotesis: Kualitas Layanan $\left(\mathrm{X}_{1}\right)$ dan Citra Perusahaan $\left(\mathrm{X}_{2}\right)$ berpengaruh terhadap $\operatorname{Kepuasan}\left(\mathrm{Y}_{1}\right)$

Struktur:

$Y_{1}=B_{1} X_{I}+B_{2} X_{2}+\varepsilon 1$

Model II

Hipotesis: Kualitas Layanan $\left(\mathrm{X}_{1}\right)$, Citra Perusahaan $\left(\mathrm{X}_{2}\right)$, Kepuasan $\left(\mathrm{Y}_{1}\right)$ berpengaruh terhadap Loyalitas Pelanggan $\left(\mathrm{Y}_{2}\right)$.

Struktur:

$Y_{2}=B_{3} X_{1}+B_{4} X_{2}+B_{5} Y_{1}+\varepsilon_{2}$

Langkah kedua, menghitung koefisien jalur yang didasarkan pada koefisien regresi. Langkah ketiga, menghitung koefisien jalur secara simultan. Uji secara keseluruhan 
ditunjukkan oleh tabel ANOVA. Langkah keempat menghitung koefisien jalur secara individu atau parsial. Uji secara individual dapat dilihat pada tabel coefficients. Jika nilai probabilitas sig. lebih dari atau sama dengan nilai probabilitas 0,05 atau (sig. $\geq 0,05)$ maka $\mathrm{H}_{\mathrm{o}}$ diterima dan Ha ditolak, artimya tidak signifikan. Jika nilai sig. kurang dari atau sama dengan nilai probabilitas 0,05 (sig. $\leq 0,05)$ sehingga, $\mathrm{H}_{\mathrm{o}}$ ditolak dan $\mathrm{Ha}$ diterima, artinya signifikan. Langkah terakhir dalam analisis jalur, meringkas dan menetapkan interpretasi dari hasil analisis yang diperoleh.

Pengujian hipotesis mediasi dapat dilakukan Uji Sobel (Sobel Test). Uji Sobel berfungsi untuk menguji kekuatan pengaruh tidak langsung pengaruh variabel kualitas layanan $\left(\mathrm{X}_{1}\right)$ terhadap loyalitas pelanggan $\left(\mathrm{Y}_{2}\right)$ melalui variabel kepuasan $\left(\mathrm{Y}_{1}\right)$ dan citra perusahaan $\left(\mathrm{X}_{2}\right)$ terhadap variabel loyalitas pelanggan $\left(\mathrm{Y}_{2}\right)$ melalui variabel kepuasan $\left(\mathrm{Y}_{1}\right)$. Pengaruh tidak langsung variabel kualitas layanan $\left(\mathrm{X}_{1}\right)$ terhadap variabel loyalitas pelanggan $\left(\mathrm{Y}_{2}\right)$ melalui variabel kepuasan $\left(\mathrm{Y}_{1}\right)$ dihitung dengan cara mengalikan koefisien jalur $\mathrm{X}$ terhadap $\mathrm{Y}_{1}(\mathrm{a})$ dengan koefisien jalur $\mathrm{Y}_{1}$ terhadap $\mathrm{Y}_{2}$ atau ab. Standar eror koefisien a dan $\mathrm{b}$ ditulis dengan $\mathrm{Sa}$ dan $\mathrm{Sb}$, besarnya standar eror tidak langsung (indirect effect) Sab.

Standard error tidak langsung (indirect effect) Sab dihitung dengan rumus berikut :

$$
\mathrm{Sab}=\sqrt{\mathrm{b}^{2} \mathrm{sa}^{2}+\mathrm{a}^{2} \mathrm{sb}^{2}+\mathrm{sa}^{2} \mathrm{sb}^{2}}
$$

Untuk menguji signifikansi pengaruh tidak langsung maka nilai z dari koefisien ab dihitung dengan rumus sebagai berikut:

$$
\mathrm{z}=\frac{a b}{S a b}
$$


Keterangan:

$\begin{array}{lll}\mathrm{Sab} & = & \text { besarnya standar eror koefisien } \mathrm{a} \\ \mathrm{Sb} & = & \text { Besarnya standar eror koefisien } \mathrm{b} \\ \mathrm{A} & = & \text { koefisien jalur } \mathrm{X}_{1} \text { terhadap } \mathrm{Y}_{1} \\ \mathrm{~B} & = & \text { koefisien jalur } \mathrm{Y}_{1} \text { terhadap } \mathrm{Y}_{2}\end{array}$

\section{HASIL DAN PEMBAHASAN}

Terdapat total 112 sampel yang digunakan dalam peneltian ini. Seluruh responden berpartisipasi dengan mengisi kuesioner yang telah disebar baik melalui media internet (online) maupun secara langsung (offline).

Tabel 2.

Karakteristik Responden

\begin{tabular}{|c|c|c|c|c|}
\hline No & Variabel & Klasifikasi & $\begin{array}{l}\text { Jumlah } \\
\text { (Orang) }\end{array}$ & $\begin{array}{c}\text { Presentase } \\
(\%)\end{array}$ \\
\hline \multirow[t]{3}{*}{1} & $\begin{array}{c}\text { Jenis } \\
\text { Kelamin }\end{array}$ & Laki - Laki & 42 & 37,5 \\
\hline & & Perempuan & 70 & 62,5 \\
\hline & & Jumlah & 112 & 100 \\
\hline \multirow[t]{5}{*}{2} & Usia (tahun) & $\leq 20$ & 13 & 11,6 \\
\hline & & $21-30$ & 73 & 65,2 \\
\hline & & $31-40$ & 14 & 12,5 \\
\hline & & $>40$ & 12 & 10,7 \\
\hline & & Jumlah & 112 & 100 \\
\hline \multirow[t]{4}{*}{3} & $\begin{array}{l}\text { Pendidikan } \\
\text { Terakhir }\end{array}$ & SMA & 74 & 66,1 \\
\hline & & Sarjana & 32 & 28,6 \\
\hline & & Pascasarjana & 16 & 5,3 \\
\hline & & Jumlah & 112 & 100 \\
\hline \multirow[t]{5}{*}{4} & Pekerjaan & Pelajar / Mahasiswa & 66 & 58,9 \\
\hline & & $\begin{array}{l}\text { PNS / Pegawai } \\
\text { Swasta }\end{array}$ & 31 & 27,7 \\
\hline & & Wiraswasta & 12 & 10,7 \\
\hline & & Lainnya & 3 & 2,7 \\
\hline & & Jumlah & 112 & 100 \\
\hline
\end{tabular}

Sumber : Data Primer Diolah, 2017 
Tabel 2. menunjukkan jumlah responden dengan jenis kelamin wanita cenderung mendominasi, sebesar 62,5 persen dari total responden dan sisanya adalah responden pria dengan sebesar 37,5 persen. Sebagian besar responden berada pada klasifikasi usia 21 - 30 tahun yakni sebanyak 73 responden atau 65,2 persen. Responden dengan pendidikan terakhir pada jenjang SMA mendominasi dengan jumlah responden sebanyak 74 orang atau 66,1 persen. Berdasarkan pekerjaan, Tabel 2 menunjukkan bahwa mayoritas jenis pekerjaan responden adalah Pelajar/Mahasiswa yaitu sebanyak 66 orang atau 58,9 persen dari total responden.

Tabel 3.

Hasil Uji Validitas

\begin{tabular}{clccc}
\hline No & Variabel & Indikator & $\begin{array}{c}\text { Koefisien } \\
\text { Korelasi }\end{array}$ & Keterangan \\
\hline \multirow{2}{*}{1} & Kualitas & $\mathrm{X}_{1.1}$ & 0,779 & Valid \\
& Layanan & $\mathrm{X}_{1.2}$ & 0,907 & Valid \\
& & $\mathrm{X}_{1.3}$ & 0,879 & Valid \\
& & $\mathrm{X}_{1.4}$ & 0,847 & Valid \\
& & $\mathrm{X}_{1.5}$ & 0,796 & Valid \\
\multirow{2}{*}{2} & Citra & $\mathrm{X}_{2.1}$ & 0,841 & Valid \\
& Perusahaan & $\mathrm{X}_{2.2}$ & 0,851 & Valid \\
& & $\mathrm{X}_{2.3}$ & 0,775 & Valid \\
3 & & $\mathrm{Y}_{1.1}$ & 0,939 & Valid \\
& & $\mathrm{Y}_{1.2}$ & 0,878 & Valid \\
& & $\mathrm{Y}_{1.3}$ & 0,931 & Valid \\
\multirow{2}{*}{4} & Lepuasan & $\mathrm{Y}_{2.1}$ & 0,861 & Valid \\
& & $\mathrm{Y}_{2.2}$ & 0,949 & Valid \\
& & $\mathrm{Y}_{2.3}$ & 0,934 & Valid \\
\hline Sumber $:$ Data Primer Diolah 2017 & & &
\end{tabular}

Hasil olah data pada Tabel 3. memperlihatkan nilai koefisien korelasi dari setiap indikator memiliki nilai yang lebih besar dari $0,3(\mathrm{r} \geq 0,30)$, ini berarti semua instrumen yang digunakan adalah valid. 
Tabel 4.

Hasil Uji Realibilitas

\begin{tabular}{clcc}
\hline No & Variabel & Cronbach's alpha & Keterangan \\
\hline 1 & Kualitas Layanan & 0,897 & Reliabel \\
2 & Citra Perusahaan & 0,760 & Reliabel \\
3 & Kepuasan & 0.903 & Reliabel \\
4 & Loyalitas Pelanggan & 0,897 & Reliabel \\
\hline \multicolumn{2}{l}{ Sumber $:$ Data Primer Diolah, 2017 }
\end{tabular}

Tabel 4. menunjukkan instrumen penelitian yaitu variabel kualitas layanan, citra perusahaan, kepuasan dan loyalitas memiliki koefisien Cronbach's Alpha lebih besar dari 0,60 sehingga pernyataan pada kuesioner tersebut reliabel.

Uji Normalitas bertujuan untuk mengetahui apakah residual dari model regresi yang dibuat berdistribusi normal atau tidak dan dapat dilihat pada Tabel 5 . dan Tabel 6.

Tabel 5.

Hasil Uji Normalitas Persamaan Regresi 1

\begin{tabular}{cc}
\hline & Unstandardized Residual \\
\hline $\mathrm{N}$ & 112 \\
Kolmogrov - Smirnov $Z$ & 1,274 \\
Asymp. Sig. $(2-$ tailed $)$ & 0,78 \\
\hline
\end{tabular}

Sumber : Data Primer Diolah, 2017

Tabel 5. menunjukkan model persamaan regresi tersebut berdistribusi normal karena nilai Asymp. Sig. (2-tailed) 0,78 lebih besar dari nilai alpha 0,05.

Tabel 6.

Hasil Uji Normalitas Persamaan Regresi 2

\begin{tabular}{cc}
\hline & Unstandardized Residual \\
\hline $\mathrm{N}$ & 112 \\
Kolmogrov - Smirnov $Z$ & 0,757 \\
Asymp. Sig. $(2-$ tailed $)$ & 0,616 \\
\hline
\end{tabular}

Sumber : Data Primer Diolah, 2017 
Tabel 6. memperlihatkan bahwa model persamaan regresi tersebut berdistribusi normal karena nilai Asymp. Sig. (2-tailed) 0,616 lebih besar dari nilai alpha 0,05 .

Uji multikolinieritas dilakukan untuk menguji apakah pada model regresi ditemukan korelasi antar variabel bebas. Adanya multikolinearitas dapat dilihat dari nilai tolerance atau variance inflation factor (VIF).

Tabel 7.

Hasil Uji Multikoliniearitas Persamaan Regresi 1

\begin{tabular}{ccc}
\hline Variabel & Tolerance & VIF \\
\hline Kualitas Layanan & 0,497 & 2,011 \\
Citra Perusahaan & 0,497 & 2,011 \\
\hline
\end{tabular}
Sumber : Data Primer Diolah, 2017

Tabel 7. menunjukkan nilai koefisien tolerance kualitas produk dan harga tidak terdapa multikolinearitas dengan nilai masing-masing adalah 0,497 > 0,1 dan nilai VIF sebesar $2,011<10$.

Uji Hetereskedastisitas bertujuan untuk mengetahui apakah dalam model regresi terjadi ketidaksamaan varians dan residual satu pengamatan ke pengamatan lain yang dilakukan dengan uji Glejser.

Tabel 8.

Hasil Uji Heteroskedastisitas Persamaan Regresi 1

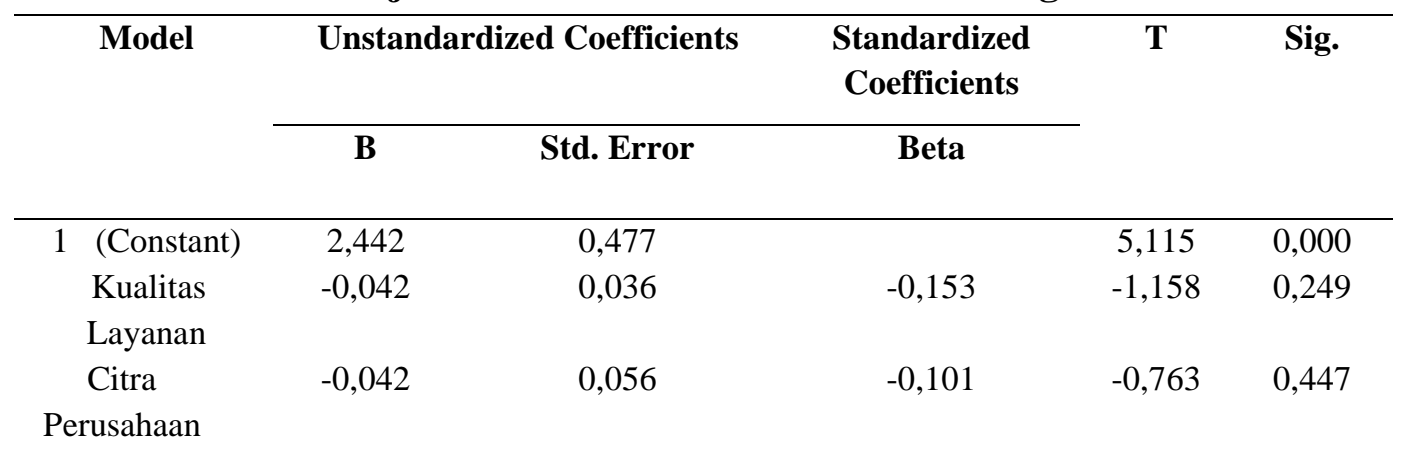


Tabel 8. memperlihatkan nilai signifikansi dari variabel kualitas layanan dan citra perusahaan secara berurutan sebesar 0,249 dan 0,447 . Nilai signifikansi keduah variabel lebih dari 0,05 , berarti tidak terdapat pengaruh antara variabel bebas terhadap absolute residual.

Tabel 9.

Hasil Uji Heteroskedastisitas Persamaan Regresi 2

\begin{tabular}{|c|c|c|c|c|c|}
\hline \multirow[t]{2}{*}{ Model } & \multicolumn{2}{|c|}{$\begin{array}{l}\text { Unstandardized } \\
\text { Coefficients }\end{array}$} & \multirow{2}{*}{$\begin{array}{c}\begin{array}{c}\text { Standardize } \\
\text { d } \\
\text { Coefficients }\end{array} \\
\text { Beta } \\
\end{array}$} & \multirow[t]{2}{*}{$\mathbf{T}$} & \multirow[t]{2}{*}{ Sig. } \\
\hline & B & Std. Error & & & \\
\hline 1 & 1,778 & 0,534 & & 3,346 & 0,01 \\
\hline $\begin{array}{c}\text { (Constant) } \\
\text { Kualitas }\end{array}$ & $-0,082$ & 0,042 & $-0,275$ & $-1,934$ & 0,056 \\
\hline $\begin{array}{l}\text { Layanan } \\
\text { Citra }\end{array}$ & 0,019 & 0,065 & 0,041 & 0,290 & 0,772 \\
\hline $\begin{array}{l}\text { Perusahaan } \\
\text { Kepuasan }\end{array}$ & 0,067 & 0,059 & 0,148 & 1,131 & 0,261 \\
\hline
\end{tabular}

Tabel 9. memperlihatkan nilai signifikansi dari variabel kualitas layanan, citra perusahaan dan kepuasan masing-masing sebesar 0,056; 0,772 dan 0,261. Nilai tersebut lebih besar dari 0,05 yang berarti tidak terdapat pengaruh antara variabel bebas terhadap absolute residual.

Tabel 10.

Hasil Analisis Jalur Persamaan Regresi 1

\begin{tabular}{|c|c|c|c|c|c|}
\hline \multirow[t]{2}{*}{ Model } & \multicolumn{2}{|c|}{ Unstandardized Coefficients } & \multirow{2}{*}{$\begin{array}{c}\begin{array}{c}\text { Standardized } \\
\text { Coefficients }\end{array} \\
\text { Beta }\end{array}$} & \multirow[t]{2}{*}{$\mathbf{t}$} & \multirow[t]{2}{*}{ Sig. } \\
\hline & B & Std. Error & & & \\
\hline 1 (Constant) & 1,813 & 0,849 & & 2,136 & 0,035 \\
\hline $\begin{array}{l}\text { Kualitas } \\
\text { Layanan }\end{array}$ & 0,242 & 0,065 & 0,365 & 3,738 & 0,000 \\
\hline $\begin{array}{c}\text { Citra } \\
\text { Perusahaan }\end{array}$ & 0,390 & 0,99 & 0,386 & 3,948 & 0,000 \\
\hline $\mathrm{R}_{1}^{2}: 0,482$ & F Statis &, 781 & $: 0,000$ & & \\
\hline
\end{tabular}

Teknik analisis yang digunakan pada pengujian data penelitian ini adalah teknik analisis jalur (path analysis). Teknik ini merupakan perluasan dari analisis 
regresi linear berganda yang bertujuan untuk menguji hubungan kausalitas dua atau lebih variabel.

Nilai $\beta_{1}$ sebesar 0,356 memiliki arti kualitas layanan berpengaruh positif terhadap kepuasan, jika faktor kualitas layanan meningkat maka kepuasan meningkat sebesar 0,356 . Nilai $\beta_{2}$ sebesar 0,386 , artinya citra perusahaan berpengaruh positif terhadap kepuasan, jika citra perusahaan meningkat maka kepuasan meningkat sebesar 0,386.

Tabel 11.

Hasil Analisis Jalur Persamaan Regresi 2

\begin{tabular}{|c|c|c|c|c|c|}
\hline \multirow[t]{2}{*}{ Model } & \multicolumn{2}{|c|}{ Unstandardized Coefficients } & \multirow{2}{*}{$\begin{array}{c}\begin{array}{c}\text { Standardized } \\
\text { Coefficients }\end{array} \\
\text { Beta }\end{array}$} & \multirow[t]{2}{*}{$\mathbf{T}$} & \multirow[t]{2}{*}{ Sig. } \\
\hline & B & Std. Error & & & \\
\hline \multicolumn{6}{|l|}{$1 \quad$ ( Constant) } \\
\hline & $-1,151$ & 0,871 & & $-1,321$ & 0,189 \\
\hline \multirow{2}{*}{$\begin{array}{l}\text { KualitasLayanan } \\
\text { Citra }\end{array}$} & 0,202 & 0,069 & 0,271 & 2,930 & 0,004 \\
\hline & 0,334 & 0,106 & 0,292 & 3,143 & 0,002 \\
\hline $\begin{array}{r}\text { Perusahaan } \\
\text { Kepuasan }\end{array}$ & 0,353 & 0,096 & 0,313 & 3,669 & 0,000 \\
\hline $\mathrm{R}^{2}: 0,594$ & F Statis & 2,720 & Sig. F : 0,000 & & \\
\hline
\end{tabular}

Nilai $\beta_{3}$ sebesar 0,271 menyatakan kualitas layanan berpengaruh positif terhadap loyalitas, jika kualitas layanan meningkat, maka loyalitas akan meningkat sebesar 0,271. Nilai $\beta_{4}$ sebesar 0,292 berarti citra perusahaan berpengaruh positif terhadap loyalitas, jika corporate image atau citra perusahaan meningkat, maka loyalitas akan meningkat sebesar 0,292 . Nilai $\beta_{5}$ sebesar 0,313 memiliki arti bahwa kepuasan berpengaruh positif terhadap loyalitas, sehingga jika kepuasan meningkat, maka loyalitas akan meningkat sebesar 0,313.

Perhitungan pengaruh error (e) menghasilkan hasil pengaruh error (e1) sebesar 0,720 dan pengaruh error (e2) sebesar 0,637. Nilai determinasi total yang diperoleh adalah sebesar 0,79 artinya 79 persen loyalitas dipengaruh oleh kualitas 
layanan, citra perusahaan, dan kepuasan sedangkan sisanya 21 persen dijelaskan oleh faktor lain yang tidak dimasukkan ke dalam model.

Pengujian Sig. F pada Tabel 11. menunjukkan Sig. F $\leq 0,05(0,000 \leq 0,05)$ maka $\mathrm{H}_{1}$ diterima yaitu kualitas layanan, citra perusahaan dan kepuasan berpengaruh secara signifikan terhadap loyalitas, sehingga model persamaan struktural telah memenuhi syarat goodness of fit melalui uji F.

Hasil analisis pengaruh kualitas layanan terhadap kepuasan menghasilkan nilai Sig. t sebesar 0,000 dengan nilai koefisien beta 0,365. Nilai Sig.t 0,000<0,05 mengindikasikan bahwa $\mathrm{H}_{\mathrm{o}}$ ditolak dan $\mathrm{H}_{1}$ diterima, dengan demikian kualitas layanan berpengaruh signifikan terhadap kepuasan. Penelitian - penelitian sebelumnya dengan hasil yang sejalan antara lain penelitian Abd - El - Salam et al. (2013), Ali et al. (2013), Kaura et al. (2015), Sandada \& Matbiri (2016), dan Djanas (2016).

Hasil analisis pengaruh citra perusahaan terhadap kepuasan menghasilkan nilai Sig. $t$ sebesar 0,000 dengan nilai koefisien beta 0,386. Nilai Sig.t 0,000 <0,05 sehingga $\mathrm{H}_{\mathrm{o}}$ ditolak dan $\mathrm{H}_{1}$ diterima, artinya citra perusahaan berpengaruh signifikan terhadap kepuasan. Penelitian terdahulu yang sesuai dengan penelitian ini antara lain Abd-El-Salam et al. (2013), Anisimova (2013), Abrudan et al. (2015), dan Sia \& Subagio (2013).

Hasil analisis pengaruh kualitas layanan terhadap loyalitas menunjukkan nilai Sig. $\mathrm{t}$ sebesar 0,000 dengan nilai koefisien beta 0,271. Nilai Sig.t 0,000 $<0,05$ mengakibatkan $\mathrm{H}_{\mathrm{o}}$ ditolak dan $\mathrm{H}_{1}$ diterima, artinya kualitas layanan berpengaruh 
signifikan terhadap loyalitas. Beberapa penelitian sebelumnya menemukan hal yang sama antara lain Muntholimah \& Rahayu (2014), dan Yunnus et al. (2013).

Hasil analisis pengaruh citra perusahaan terhadap loyalitas menghasilkan nilai Sig. t sebesar 0,000 dengan nilai koefisien beta 0,292. Nilai Sig.t 0,000<0,05 menunjukkan bahwa $\mathrm{H}_{0}$ ditolak dan $\mathrm{H}_{1}$ diterima, artinya citra perusahaan berpengaruh signifikan terhadap loyalitas. Hasil penelitian ini sejalan dengan penelitian yang dilakukan oleh Normasari dkk. (2013) dan Singh (2014).

Hasil analisis pengaruh kepuasan terhadap loyalitas menunjukkan nilai Sig. $\mathrm{t}$ sebesar 0,000 dan nilai koefisien beta 0,313. Nilai Sig.t 0,000 $<0,05$ menandakan bahwa $\mathrm{H}_{\mathrm{o}}$ ditolak dan $\mathrm{H}_{1}$ diterima, artinya kepuasan memiliki pengaruh yang signifikan terhadap loyalitas. Beberapa penelitian terdahulu memiliki hasil yang sesuai dengan penelitian ini, antara lain Izogo \& Ogba (2014) dan Singh \& Takur (2012).

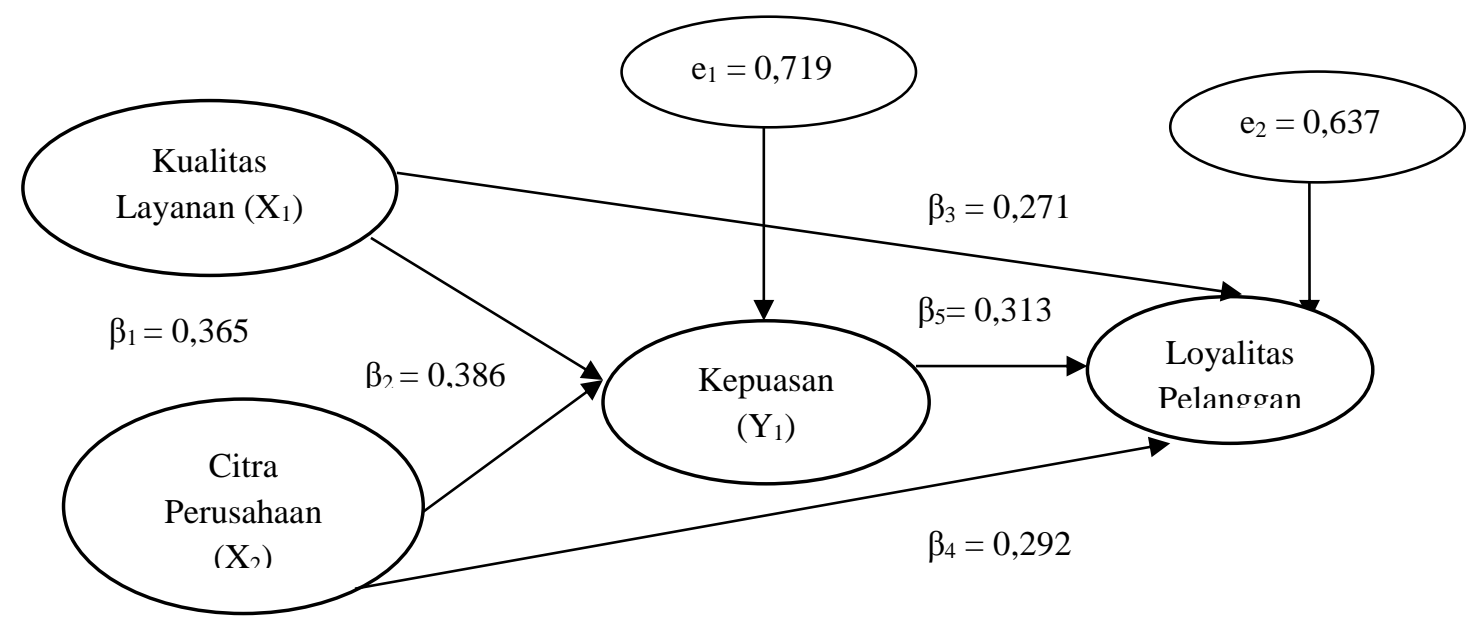

Gambar 1. Hasil Koefisien Jalur pada Hipotesis Penelitian

Sumber : Data Primer Diolah, 2017 
Pengaruh total antar variabel dapat dihitung berdasarkan besarnya pengaruh langsung dan pengaruh tidak langsung antar variabel. Perhitungan pengaruh masing - masing varibel penelitian dicantumkan pada Tabel 12.

Tabel 12.

\section{Pengaruh Langsung, Pengaruh Tidak Langsung serta Pengaruh Total Kualitas Layanan $\left(\mathbf{X}_{1}\right)$, Citra Perusahaan $\left(\mathbf{X}_{2}\right)$, Kepuasan $\left(\mathbf{Y}_{1}\right)$, dan Loyalitas Pelanggan $\left(\mathrm{Y}_{2}\right)$}

\begin{tabular}{cccc}
\hline $\begin{array}{c}\text { Pengaruh } \\
\text { Variabel }\end{array}$ & $\begin{array}{c}\text { Pengaruh } \\
\text { Langsung }\end{array}$ & $\begin{array}{c}\text { Pengaruh Tidak langsung Melalui } \\
\text { Kepuasan }\end{array}$ & $\begin{array}{c}\text { Pengaruh } \\
\text { Total }\end{array}$ \\
\hline $\mathrm{X}_{1} \rightarrow \mathrm{Y}_{1}$ & 0,365 & - & - \\
$\mathrm{X}_{2} \rightarrow \mathrm{Y}_{1}$ & 0,396 & - & - \\
$\mathrm{X}_{1} \rightarrow \mathrm{Y}_{2}$ & 0,271 & 0,114 & 0,385 \\
$\mathrm{X}_{2} \rightarrow \mathrm{Y}_{2}$ & 0,292 & 0,121 & 0,413 \\
$\mathrm{Y}_{1} \rightarrow \mathrm{Y}_{2}$ & 0,313 & - & - \\
\hline Sumber $:$ Data Primer Diolah,2017.
\end{tabular}

Hasil pada Tabel 12. memperlihatkan pengaruh langsung variabel kualitas layanan terhadap loyalitas pelanggan dengan nilai koefisien beta 0,271 dan pengaruh tidak langsung yang dimediasi oleh kepuasan dengan nilai koefisien beta sebesar 0,114 menghasilkan pengaruh total sebesar 0,385. Selain itu, tabel juga menunjukkan pengaruh langsung variabel citra perusahaan terhadap loyalitas pelanggan dengan nilai koefisien beta sebesar 0,292 serta pengaruh tidak langsung yang dimediasi oleh kepuasan memperoleh nilai beta sebesar 0,121 dan menghasilkan pengaruh total sebesar 0,413.

Nilai signifikansi dan hubungan tidak langsung antara variabel independen dengan variabel dependen yang dimediasi oleh variabel mediator dan nilai signfiknasinya dapat diuji menggunakan Uji Sobel. Jika nilai perhitungan Z lebih besar dari 1,96 (tingkat kepercayaan 95 persen), maka variabel mediasi dinilai secara signifikan memediasi hubungan antara variabel dependen (terikat) dan variabel independen (bebas). 
Hasil Uji Sobel dalam penelitian ini menunjukkan hasil tabulasi $\mathrm{Z}=2,7867$ $>1,96$ serta tingkat signifikansi $0,0053<0,05$ artinya variabel mediasi yakni kepuasan dinilai secara signifikan memediasi kualitas layanan dengan loyalitas. Temuan ini juga sesuai dengan beberapa penelitian sebelumnya antara lain penelitian Lei \& Julibert (2012), Safitri dkk. (2016) Kaura et al. (2014) dan Putri dkk. (2015).

Hasil Uji Sobel dalam penelitian ini menunjukkan bahwa hasil tabulasi Z = 2, $4541>1,96$ dengan tingkat signifikansi $0,0141<0,05$ yang berarti variabel mediasi yakni kepuasan dinilai secara signifikan memediasi kualitas layanan dengan loyalitas. Penelitian terdahulu dengan hasil yang sejalan antara lain penelitian Safitri dkk. (2016) dan Saputra (2013).

\section{SIMPULAN DAN SARAN}

Berdasarkan pembahasan hasil penelitian yang telah dilakukan, maka dapat disimpulkan bahwa, kualitas layanan berpengaruh positif dan signifikan terhadap kepuasan. Citra perusahaan berpengaruh positif dan signifikan terhadap kepuasan. Kualitas layanan berpengaruh positif dan signifikan terhadap loyalitas pelanggan. Citra perusaan berpengaruh positif dan signifikan terhadap loyalitas pelanggan. Kepuasan berpengaruh positif dan signifikan terhadap loyalitas pelanggan. Kepuasan mampu memediasi kualitas layanan dengan loyalitas pelanggan. Kepuasan mampu memediasi citra perusahaan dengan loyalitas pelanggan.

Saran yang dapat diberikan berdasarkan kesimpulan yang didapat adalah sebagai berikut : pihak Lion Air dapat meningkatkan rasa keyakinan pelanggan 
bahwa Lion Air menjamin keselamatan dan kenyamanan pelanggan dengan selalu mematuhi regulasi tentang standar keselamatan penerbangan, serta rutin melakukan sertifikasi seperti sertifikasi IOSA \& ISSA. Pihak Lion Air dapat memperbaiki sistem public relation yang sebelumnya rentan mendapatkan komplain dari pelanggan. Lion Air sebaiknya memberikan kemudahan bagi pelanggan untuk menjalin komunikasi dengan pihak manajemen Lion Air. Pihak Lion Air dapat memperbaiki layanan yang diberikan diberbagai aspek layanan misalnya dengan selalu memastikan kabin selalu dalam keadaan bersih dan nyaman, memperbaiki time management serta menjamin karyawan selalu ramah dan sopan. Faktor faktor yang mempengaruhi loyalitas pelanggan tidak hanya ditinjau dari aspek kualitas layanan, citra perusahaan, dan kepuasan. Penelitian selanjutnya dapat menyertakan variabel lain yang terkait faktor - faktor yang mempengaruhi loyalitas pelanggan.

\section{REFRENSI}

Abd - El - Salam,Shawky, and El - Nahas. 2013.The Impact Of Corporate Image And Reputation On Service Quality, Customer Satisfaction And Customer Loyalty: Testing The Mediating Role.Case Analysis In An International Service Company. The Business \& Management Review, 3(2) : 177 - 196.

Abrudan. I - N and Dabija.D. 2015. The Relationship among Image Satisfaction and Loyality - Innovative Factor of Competitiveness for Shopping Centers. Amfiteatru Economic, 17(39) : 536 - 552.

Anisimova, Tatiana. 2013. Evaluating The Impact of Corporate Brand on Consumer Satisfaction. Asia Pacific Journal of Marketing and Logistics, 25(4) : $561-589$.

Ali, F., Zhou, Y., Hussain, K., Nair, P.K., Ragavan, N.A. 2016. Does Higher Education Service Quality Effect Student Satisfaction, Image and Loyalty. Quality Assurance in Education, 24(1): 70 - 94. 
Djanas, Asmiati. 2016. Kualitas Pelayanan dan Citra Perusahaan terhadap Kepuasan serta Dampaknya terhadap Loyalitas Wisatawan. Jurnal Sains Manajemen, 2(2) :184-192.

Ganiyua, Uche, Elizabeth. 2012. Is Customer Satisfaction An Indicator of Customer Loyalty. Australian Journal of Business and Management Research, 2(07) : 14-20.

Griffin, Jill. 2005. Customer Loyalty : Menumbuhkan \& Mempertahankan Kesetiaan Pelanggan. Jakarta : Erlangga.

Huda dan Wahyuni. 2012. Analisis Pengaruh Kualitas Layanan Internet Banking dan Tingkat Kepuasan terhadap Loyalitas Nasabah pada PT Bank Rakyat Indonesia (Persero) Tbk Kantor Cabang Pembantu Jamsostek Jakarta. Bussiness \& Management Review, 2(2) : 243 - 254.

Izogo, Ernest Ameka and Ogba, Ike - Alechi. 2015. Service Quality, Customer Satisfaction And Loyalty In Automobile Repair Services Sector.International Journal of Quality \& Reliability Management, 32 (3) : 250-269.

Jasfar, Farida. 2005. Manajemen Jasa Pendekatan Terpadu. Bogor : Ghalia Indonesia.

Kaur and Soch. 2013. Mediating roles of commitment and corporate image in the formation of customer loyalty. Journal of Indian Business Research, 5(1) : 33 -51 .

Kaura, Prasadh, and Sharma.2015. Service Quality, Service Convenience, Price And Fairness, Customer Loyalty, And The Mediating Role Of Customer Satisfaction. International Journal Of Bank Marketing, 33(4) : 404-422.

Kotler dan Keller. 2009. Manajemen Pemasaran. Jakarta: Erlangga.

Lei, P. and Jolibert, A. 2012. A Three - Model Comparison of The Relationship Between Quality, Satisfaction, and Loyalty : An Empirical Study of The Chinese Healthcare System. BMC Health Services Research : 12:436.

Muntholimah, Atin dan Rahayu. 2014. Pengaruh Citra Perusahaan dan Kualitas Layanan terhadap Loyalitas Pengguna Jasa JNE Surabaya. Jurnal Ilmu \& Riset Manajemen,3(10) : 1-25.

Normasari, S., Kumadji,S. dan Kusumawati,A. 2013. Pengaruh Kualitas Pelayanan Terhadap Kepuasan Pelanggan, Citra Perusahaan dan Loyalitas Pelanggan (Survei pada Tamu Pelanggan yang Menginap di Hotel Pelangi Malang). Jurnal Administrasi Bisnis (JAB), 6(2) : 1-9.

Parasuraman, A., V. A. Zeithaml, dan L.L. Berry. 1998. SERVQUAL: A MultipleItem Scale for Measuring Consumer Perceptions of Service Quality. Journal of Retailing, 64( 1) : $12-40$. 
P. Singh, A. 2012. Impact of Service Quality on Customer Satisfaction and Loyalty in The Context of Retail Outlets in Db City Shopping Mall Bhopal. International Journal of Management Research and Review, 2(12) : 334 - 344.

Putri,Suharyono, dan Fanani. 2015. Pengaruh Kualitas Pelayanan Terhadap Kepuasan dan Loyalitas Pelanggan (Survey Pada Pelanggan Auto2000 Waru Surabaya). Jurnal Administrasi Bisnis (JAB), 1(1) : 1 - 10.

Putri, W. I. 2014. Pengaruh Kualitas Pelayanan Terhadap Kepuasan Serta Citra Perusahaan Dalam Membangun Loyalitas Konsumen PT.KAI. E- Journal Graduate Unpar,1(1) : 141-149.

Safitri.E,Rahayu.M dan Indrawat N.K.2016. Pengaruh Kualitas Pelayanan dan Citra Perusahaan Terhadap Kepuasan Pelanggan dan Loyalitas Pelanggan Service Center (Studi Pada Pelanggan Samsung Service Center di Kota Malang). Jurnal Ekonomi Bisniss,21(1) : 90-104.

Sandada.M,Matibri.B. 2016. An Investigation Into The Impact Of Service Quality, Frequent Flier Programs And Safety Perception On Satisfaction And Customer Loyalty In The Airline Industry In Southern Africa. South East European Journal of Economics and Business, 11 (1) : 41-53.

Saputra, F.I.2013. Kualitas Layanan, Citra dan Pengaruhnya terhadap Loyalitas melalui Kepuasan Pelanggan (Studi Pada PT Bank BNI 46 Sentra Kredit Kecil Surabaya). Jurnal Aplikasi Majemen, 11(3) : 445 - 457.

Selnes, F. 1993. An Examination of the Effect of Product Performance on Brand Reputation, Satisfaction and Loyalty. European Journal of Marketing, 27(9) : $19-35$.

Sia, T.F dan Subagio.H. Analisa Pengaruh Price, Service Quality, dan Corporate Image terhadap Customer Loyalty dengan Customer Satisfaction Sebagai Variabel Intervening Konsumen IPO Korean Cafe dan Restaurant Surabaya. 2014. Jurnal Manajemen Pemasaran, 1(1) : 1-8.

Singh, Balgopal. 2014. Impact of Corporate Branding Strategy on the consumer loyalty: An Empirical Investigation. International Journal of Marketing and Business Communication, 3(1) : 29 - 34 .

Sumarwan, dkk. 2010. Pemasaran Strategik Perspektif Value-Based Marketing \& Pengukuran Kinerja. Bogor: IPB Press.

Sutojo, Siswanto. 2004. Membangun Citra Perusahaan. Jakarta : Damar Mulia Pustaka.

Sondakh, Conny. 2014. Kualitas Layanan, Citra Merek dan Pengaruhnya terhadap Kepuasan Nasabah dan Loyalitas Nasabah Tabungan (Studi pada Nasabah Taplus BNI Cabang Manado). Jurnal Riset Bisnis dan Manajemen. 3(1) : 19 -32 . 
E-Jurnal Manajemen Unud, Vol. 7, No. 6, 2018: 3059-3085

Suyana Utama, Made. 2016. Aplikasi Analisis Kuantitatif. Denpasar: CV. Sastra Utama.

Tjandra, dkk. 2016. Analisa Pengaruh Citra Perusahaan terhadap Loyalitas Pelanggan melalui Kepuasan Pelanggan sebagai Variabel Perantara di Restoran Boncafe Surabaya. Jurnal Hospitality dan Manajemen Jasa, 4(1) : $37-51$.

Wijayanto. 2013. Pengaruh Kualitas Pelayanan Terhadap Kepuasan dan Loyalitas Nasabah Bank. Jurnal Ekonomi Manajemen Sumber Daya, 17(1) : 38 - 54.

Wungow, Richie. 2013. Kualitas Layanan, Citra, Nilai dan Kepuasan Pengaruhnya Terhadap Loyalitas Pelanggan Hotel Rock Rand Manado. Jurnal EMBA, 3(1) : $90-98$.

Yunus, Bojei, and Rashid.2013. Service Quality towards Customer Loyalty in Malaysia's Domestic Low Cost Airline Services. International Journal of eEducation, e-Business, e-Management. e-Learning, 3(4) : 333 - 336. 